\title{
Novel Parameter Identification Method for Lithium- Ion Batteries Based on Curve Fitting
}

\author{
Milos Lukic ${ }^{1}$, Paolo Giangrande ${ }^{1}$, Christian Klumpner ${ }^{1}$, Michael Galea ${ }^{2}$ \\ ${ }^{1}$ PEMC, University of Nottingham, Nottingham, United Kingdom \\ ${ }^{2}$ Key Laboratory of More Electric Aircraft Technology of Zhejiang Province, University of Nottingham Ningbo China \\ Milos.Lukic@nottingham.ac.uk
}

\begin{abstract}
This paper describes a new curve-fitting lithium-ion battery parameter identification method for equivalent circuit models. The current pulse/relaxation test is carried out and the corresponding terminal voltage is used for extracting the battery model parameters. Analysis and fitting of the waveform is performed for both pulse and relaxation periods without assuming the initial conditions of the associated $R C$ branches. This approach is demonstrated for $2^{\text {nd }}$ order model using commercial battery cell and model results are presented and compared against experimental finding revealing a good agreement.
\end{abstract}

Keywords-Batteries, modelling, parameter identification, energy storage device.

\section{INTRODUCTION}

Recent advancements in the chemistry of lithium-ion technology enabled more extensive use, commercialisation, and research interest of these batteries not only in conventional electric propulsion applications such as electric vehicles, city buses, etc., but also in aerospace applications for instance, aircraft electric taxiing [1], [2] and helicopter rotor energy harvesting [3]. Accordingly, their modelling is a critical step when designing energy storage devices for a specific application, identifying operating limits or developing efficient battery management systems (BMS).

In general, battery's models can be classified into three categories: electrochemical models, empirical models, and equivalent circuit models (ECM) [4], with the first being most detailed and accurate. However, its inputs are parameters not found in datasheets easily such as electrode thickness or electrolyte concentration [5]. Furthermore, they are computationally intensive as the models include many sets of nonlinear partial differential equations (PDEs) in the time and space domain [6]. Although numerous reduced models have been implemented by simplifying the PDEs to ordinary differential equations [4], [7], finding model's parameters yet remains a challenge. In addition, a few software programmes exist nowadays to aid the electrochemical modelling, but they are not practical if the models are to be developed quickly and if there is lacking on the knowledge of electrochemistry. On the other hand, empirical models are obtained from datasheets or measurements and they model batteries using specific formulas to represent only a particular behaviour (e.g., Peukert's model predicts runtime), and they cannot guarantee the correct model behaviour if subjected to loads other than one used for obtaining empirical equation law [6].

This work is funded by the INNOVATIVE doctoral programme. The INNOVATIVE programme is partially funded by the Marie Curie Initia Training Networks (ITN) action (project number 665468) and partially by the Institute for Aerospace Technology (IAT) at the University of Nottingham.
ECMs are undoubtedly the most popular models due to their simplicity and low computational burden. Moreover, they have an acceptable ratio of accuracy and mathematical complexity and as such, are commonly implemented in BMS or used in design procedures and simulations. Due to the existence of many electrical elements, the possibilities for ECM topology are infinite. However, the most popular configurations are Thevenin's models that are comprised of a voltage source, an internal resistance and n sets of RC pairs, as shown in Fig. 1. Circuit with $\mathrm{n}=0$ is commonly called Rint or zero-order model and it is used for design purposes, whereas models with $n>1$ are employed in dynamic simulations.

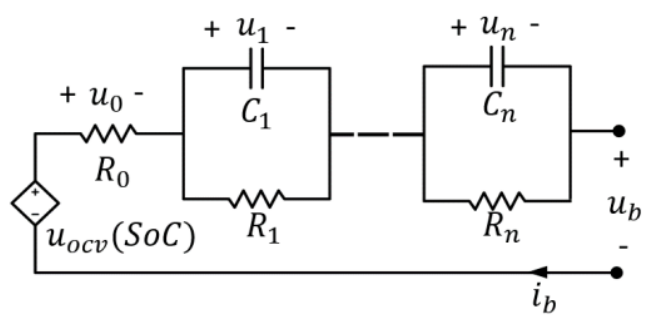

Fig. 1. Thevenin's battery ECM with $n R C$ circuits.

In this paper, a novel method of identifying the parameters of the circuit from Fig. 1 based on curve fitting is presented. The paper is organised as follows. The following section explains and discusses the conventional approaches of battery parameter's identification. Then, the proposed estimation method and its benefits are systematically presented in Section III. The Panasonic NCR18650B has been selected as benchmark to test the introduced technique and the obtained ECM parameters are shown in Section IV. In addition, the developed model is validated and compared to the experimental results, and to the results of conventional modelling approach. Finally, conclusions and considerations are drawn in Section V.

\section{PARAMETERS IDENTIFICATION}

The parameter extraction procedure aims to identify values of all elements of the circuit from Fig. 1., which are namely open circuit voltage (OCV or $\left.\mathrm{u}_{\mathrm{ocv}}\right)$, internal resistance $\mathrm{R}_{0}$, and polarisation resistance-capacitance pairs $\left(R_{n}, C_{n}\right)$. All the mentioned parameters are highly dependent on the state of charge of the battery (SoC), and thus they have to be found considering SoC variation. Moreover, these dependencies are seldom found in datasheets, and thus they are obtained from specifically designed experiments. The best-known and most straightforward procedure is for the battery to be exposed to the set of constant current pulses (CP) and rest/relaxation periods (RP). During CPs, the SoC decreases whereas it remains constant for the period of RPs (Fig. 2). 


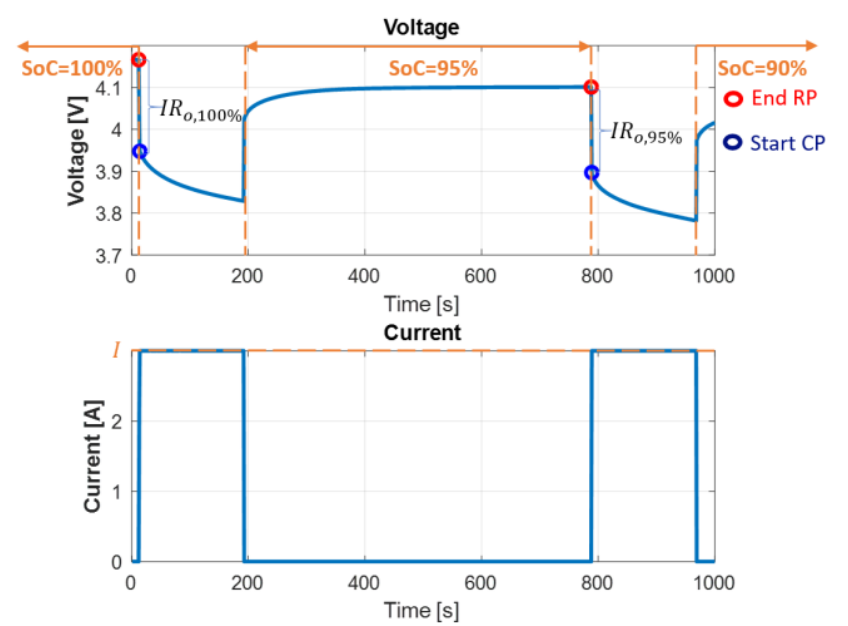

Fig. 2. Battery terminal voltage $\left(\mathrm{u}_{\mathrm{b}}\right)$ and current $\left(\mathrm{i}_{\mathrm{b}}\right)$ during two CPs.

The amplitude and duration of the $\mathrm{CP}$ are related to the desired decrease of SoC throughout one pulse $(\Delta \mathrm{SoC})$. Usually, $\Delta \mathrm{SoC}$ is in the range of $10 \%$ or $5 \%$. Sometimes, a smaller $\Delta \mathrm{SoC}$ is preferred outside $[10 \% \div 90 \%] \mathrm{SoC}$ interval, because parameters tend to vary more in $[0 \% \div 10 \%]$ and $[90 \% \div 100 \%]$ intervals [8]. The choice of $\Delta \mathrm{SoC}$ represents a compromise between the total experiment time and desired accuracy. For example, if $2 \% \Delta \mathrm{SoC}$ is selected, the interpolation of parameters will be more precise, but on the other hand there will be $\mathrm{N}=50$ rest periods which are usually very lengthy. The length of RPs is related to the OCV identification.

The $\mathrm{u}_{\mathrm{ocv}}$ at a particular $\mathrm{SoC}$ is determined by measuring the battery terminal voltage $\left(\mathrm{u}_{\mathrm{b}}\right)$ at the end of each RP (i.e., red markers in Fig. 2). Consequently, the more prolonged is the RP, the battery terminal voltage at the end of the RP will be closer to the OCV. This is because having longer rest times assure that when the battery voltage is measured at the end of RP, all polarisation dynamics are finished (i.e., $\mathrm{u}_{1}=\ldots=\mathrm{u}_{\mathrm{n}}=0$ ), and hence $u_{b}=u_{\text {ocv }}$ [9]. In general, there is no consensus on how long the RP should be. In literature, the RPs are short as 8 minutes [10], 10 minutes [11] and extended as $1 \mathrm{~h}$ [8]. Finally, the duration of RP should be decided in conjunction with the desired $\triangle \mathrm{SoC}$ considering the total time of the experiment. If in the previous example (i.e., $\Delta \mathrm{SoC}=2 \%$ ) RPs are 30 minutes long, experiment would last at least 1500 minutes, which is $25 \mathrm{~h}$.

The internal resistance $\mathrm{R}_{0}$ can also be computed easily from the battery terminal voltage waveform. It is calculated from the instantaneous voltage drop as in (1), where $t_{\text {relax,end }}$ and $\mathrm{t}_{\text {pulse,start }}$ are time instants just before and after the CP starts, respectively (Fig. 2).

$$
\mathrm{R}_{0}=\left(\mathrm{u}_{\mathrm{b}}\left(\mathrm{t}_{\text {relax,end }}\right)-\mathrm{u}_{\mathrm{b}}\left(\mathrm{t}_{\text {pulse, start }}\right)\right) / \mathrm{I}
$$

Contrary to the calculation of $\mathrm{u}_{\mathrm{ocv}}(\mathrm{SoC})$ and $\mathrm{R}_{\mathrm{o}}(\mathrm{SoC})$, which are straightforward, many approaches exist for $\left(\mathrm{R}_{n}, \mathrm{C}_{\mathrm{n}}\right)$ identification, which are continuously subjected to discussion, proposal of new methods and improvements of the existing ones. Even so, the majority of the identification procedures are based on analysing the voltage of all RC circuits $\left(\mathrm{u}_{\tau}\right)$, which can be easily found as in (2) once $\mathrm{u}_{\mathrm{ocv}}(\mathrm{SoC})$ and $\mathrm{R}_{\mathrm{o}}(\mathrm{SoC})$ are known.

$$
\mathrm{u}_{\tau}=\sum_{\mathrm{i}=1}^{\mathrm{n}} \mathrm{u}_{\mathrm{i}}=\mathrm{u}_{\mathrm{ocv}}(\mathrm{SoC})-\mathrm{R}_{\mathrm{o}} \mathrm{i}_{\mathrm{b}}-\mathrm{u}_{\mathrm{b}}
$$

In (2), $u_{i}$ is the voltage of $i^{\text {th }} R C$ pair and $n$ is the number of $R C$ circuits.

In a large number of studies, polarisation parameters are extracted from the relaxation periods of $\mathrm{u}_{\tau}$ due to two crucial reasons: 1.) SoC is constant, and 2.) analytical expression of polarisation voltage is simpler than during $\mathrm{CP}$. Therefore, methods are broadly divided into analytical based on simple equations [12] and fitting exponential functions to $u_{\tau}$ using least square method [10], [13]. Nevertheless, in both cases in order to make calculations easier, most of the methods rely on the fact of the sufficiently long pulse and rest periods. In case of analytical approach this assumption allows splitting of RC dynamics into independent intervals or in case of curve fitting approach it allows easier calculation of initial conditions.

Even though there are studies that propose a derivation from CP part of $u_{\tau}$ waveform [14], there are no studies that combine extraction from both CP and RP. In the following section, it is explained how battery parameters can be obtained using both pulse and relaxation periods of $\mathrm{u}_{\tau}$ via curve fitting without presuming any assumptions regarding initial voltages of RC circuits. It is also recognized that ECM parameters besides SoC, depend on current rate, temperature current direction, and calendar and cycle life. Thus, one benefit of the proposed method is that two sets of the parameters can be derived since estimation is also estimated during $\mathrm{CP}$. The two sets are: 1.) with the presence of current (I $\neq 0$; i.e. $\mathrm{CP})$ and 2 .) without load current $(\mathrm{I}=0$; i.e. RP). This improves the accuracy of the model keeping unchanged the experimental procedure.

\section{PROPOSED METHOD OF RC IDENTIFICATION}

The beginning of the procedure for the novel approach is the same as for conventional ones, i.e., the input is $\mathrm{u}_{\tau}$ obtained from the pulse/relaxation experimental procedure. The new technique is based on the least square method by fitting multiple exponential functions to $u_{\tau}$. Specifically, the voltage of the $i^{\text {th }}$ $\mathrm{RC}$ circuit can be expressed analytically as:

$$
\begin{gathered}
u_{i, P N}=U_{0 i, P N} e^{-\frac{t}{\tau_{i, P N}}}+\left(1-e^{-\frac{t}{\tau_{i, P N}}}\right) R_{i} I, \quad I \neq 0 \\
u_{i, R N}=U_{0 i, R N} e^{-\frac{t}{\tau_{i, R N}}}, I=0
\end{gathered}
$$

where $\mathrm{U}_{0 \mathrm{i}, \mathrm{PN}}$ and $\mathrm{U}_{0 \mathrm{i}, \mathrm{RN}}$ are initial voltages of the $\mathrm{i}^{\text {th }} \mathrm{RC}$ branch at the beginning of the $\mathrm{N}^{\text {th }} \mathrm{CP}$ and $\mathrm{RP}$ respectively, whereas $\tau_{i, P N}$ and $\tau_{i, R N}$ are time constants of the $i^{\text {th }}$ RC branch during the $\mathrm{N}^{\text {th }} \mathrm{CP}$ and RP respectively. In this paper, the ECM with $\mathrm{n}=2$ $\mathrm{RC}$ sets is selected because it represents good fit between complexity and accuracy. As a result, the experimental $\mathrm{u}_{\tau}$ can be fitted using following function $\mathrm{f}_{\mathrm{N}}$ :

$$
\begin{gathered}
f_{P, N}=a+\left(U_{01, P N}-a\right) e^{-b t}+c+\left(U_{02, P N}-c\right) e^{-d t} \\
f_{R, N}=U_{01, R N} e^{-e t}+U_{02, R N} e^{-g t}
\end{gathered}
$$

Compared to other fitting methods, in this approach no assumptions are made regarding initial voltages. Instead, initial voltages are analytically calculated before each $\mathrm{CP}$ and $\mathrm{RP}$ fitting. For this purpose, $\mathrm{u}_{\tau}$ needs to be fitted during both $\mathrm{CP}$ and $\mathrm{RP}$ and then those fitted equations are used for calculations of initial conditions as in (5). 


$$
\begin{aligned}
& \mathrm{U}_{0 \mathrm{i}, \mathrm{PN}}=\mathrm{u}_{\mathrm{i}, \mathrm{R}(\mathrm{N}-1)}\left(\mathrm{t}=\mathrm{t}_{\mathrm{relax}}\right)=\mathrm{U}_{0 \mathrm{i}, \mathrm{R}(\mathrm{N}-1)} \mathrm{e}^{-\frac{\mathrm{t}_{\mathrm{r} \text { elax }}}{\tau_{\mathrm{i}, \mathrm{R}(\mathrm{N}-1)}}}
\end{aligned}
$$

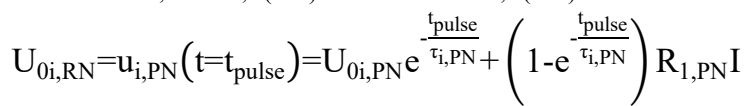

Practically, the initial voltage of the $i^{\text {th }}$ branch at the beginning of the $\mathrm{N}^{\text {th }} \mathrm{CP}$ is equal to the $\mathrm{i}^{\text {th }}$ branch relaxation voltage prior to the pulse at the time $t_{\text {relax }}$ (i.e., at the end of $\left.(\mathrm{N}-1)^{\text {th }} \mathrm{RP}\right) \mathrm{u}_{\mathrm{i}, \mathrm{R}(\mathrm{N}-1)}\left(\mathrm{t}=\mathrm{t}_{\text {relax }}\right)$. Similarly, the initial voltage of the $i^{\text {th }}$ branch at the beginning of the $\mathrm{N}^{\text {th }} \mathrm{RP}$ is equal to the $i^{\text {th }}$ branch pulse voltage at the time $t_{\text {pulse }}$ (i.e., end of the $\mathrm{N}^{\text {th }} \mathrm{CP}$ ) $\mathrm{u}_{\mathrm{i}, \mathrm{PN}}\left(\mathrm{t}=\mathrm{t}_{\text {pulse }}\right)$. It is evident that the procedure requires that fitted voltages are known before each $\mathrm{U}_{0 \mathrm{i}, \mathrm{PN}}$ and $\mathrm{U}_{0 \mathrm{i}, \mathrm{RN}}$ calculations.

Initial conditions for the first $\mathrm{CP}$ are equal to zero (i.e., $\mathrm{U}_{01, \mathrm{P} 1}=\mathrm{U}_{01, \mathrm{P} 2}=0$ ), since the system is in equilibrium before the test. Using (4a), $\mathrm{u}_{\tau}$ is fitted for the $1^{\text {st }} \mathrm{CP}$ (i.e., a,b,c and $\mathrm{d}$ are determined), from which initial conditions for the $1^{\text {st }} \mathrm{RP}$ can be computed (5b). Similarly, then, using ( $4 b) \mathrm{u}_{\tau}$ is fitted for the $1^{\text {st }}$ RP (i.e., e and $f$ are calculated), thus initial conditions for $2^{\text {nd }}$ $\mathrm{CP}$ can be assessed (5a). This procedure is repeated until the last RP is reached. The flowchart of the method is shown in Fig. 3.

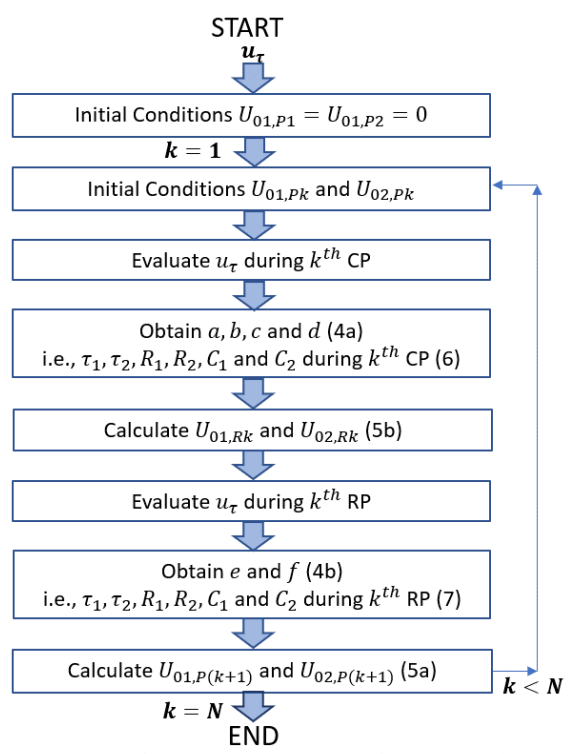

Fig. 3. Flowchart of the proposed extraction methodology.

Coefficients of the fitting a,b,c and $d$ are related to the parameters of the ECM from Fig. 1 and can be determined by comparing equations (4a) and (5a). Hence, parameters of the ECM during the pulse (i.e., $\mathrm{I} \neq 0$ ) are:

$$
\left\{\begin{array}{l}
\mathrm{R}_{1, \mathrm{PN}}=\frac{\mathrm{a}}{\mathrm{I}}, \tau_{1, \mathrm{PN}}=\frac{1}{\mathrm{~b}}, \mathrm{C}_{1, \mathrm{PN}}=\frac{\tau_{1, \mathrm{PN}}}{\mathrm{R}_{1, \mathrm{PN}}} \\
\mathrm{R}_{2, \mathrm{PN}}=\frac{\mathrm{c}}{\mathrm{I}}, \tau_{2, \mathrm{PN}}=\frac{\mathrm{d}}{\mathrm{b}}, \mathrm{C}_{2, \mathrm{PN}}=\frac{\tau_{2, \mathrm{PN}}}{\mathrm{R}_{2, \mathrm{PN}}} \quad \mathrm{I} \neq 0
\end{array}\right.
$$

Likewise, ECM's parameters in relaxation (i.e., no current) are obtained by comparing equations (4b) and (5b) as in (7):

$$
\left\{\begin{array}{l}
\mathrm{R}_{1, \mathrm{RN}}=\frac{\mathrm{U}_{01, \mathrm{RN}}}{\mathrm{I}}, \tau_{1, \mathrm{RN}}=\frac{1}{\mathrm{e}}, \mathrm{C}_{1, \mathrm{RN}}=\frac{\tau_{1, \mathrm{RN}}}{\mathrm{R}_{1, \mathrm{RN}}}, \quad I=0 \\
\mathrm{R}_{2, \mathrm{RN}}=\frac{\mathrm{U}_{02, \mathrm{RN}}}{\mathrm{I}}, \tau_{2, \mathrm{RN}}=\frac{1}{\mathrm{~g}}, \mathrm{C}_{2, \mathrm{RN}}=\frac{\tau_{2, \mathrm{RN}}}{\mathrm{R}_{2, \mathrm{RN}}}
\end{array}\right.
$$

\section{MODEL DEVELOPMENT}

\section{A. Test for parameter identification}

Parameter estimation method and model validation are carried out on a popular Panasonic NCR18650B cell, whose characteristics are listed in Table I. BK Precision 8602 Programmable DC Electronic Load is employed to generate constant current pulses and it is remotely controlled from host PC through USB communication, via BK Precision software (Fig. 4). Besides, the electronic load was also used for data acquisition (16bit $\mathrm{A} / \mathrm{D}$ converter and $1 \mathrm{~Hz}$ sampling frequency), with data directly being saved in the host PC's memory.

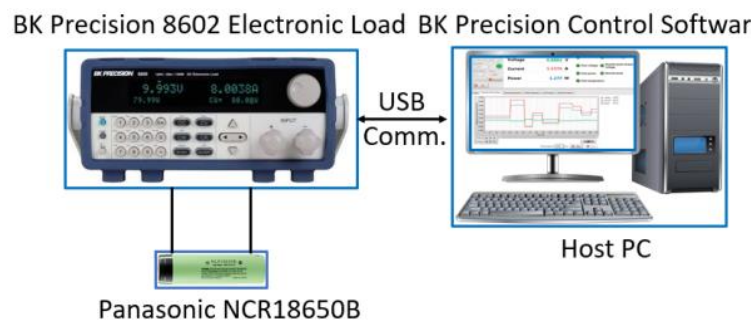

Fig. 4. Experimental setup

TABLE I. PANASONIC NCR18650B CELL PARAMETERS

\begin{tabular}{|c|c|}
\hline Name & Value \\
\hline Max. capacity $\mathrm{Q}_{\max }[\mathrm{mAh}]$ & 3400 \\
\hline Nominal voltage [V] & 3.6 \\
\hline Max. current [A] & 5 \\
\hline
\end{tabular}

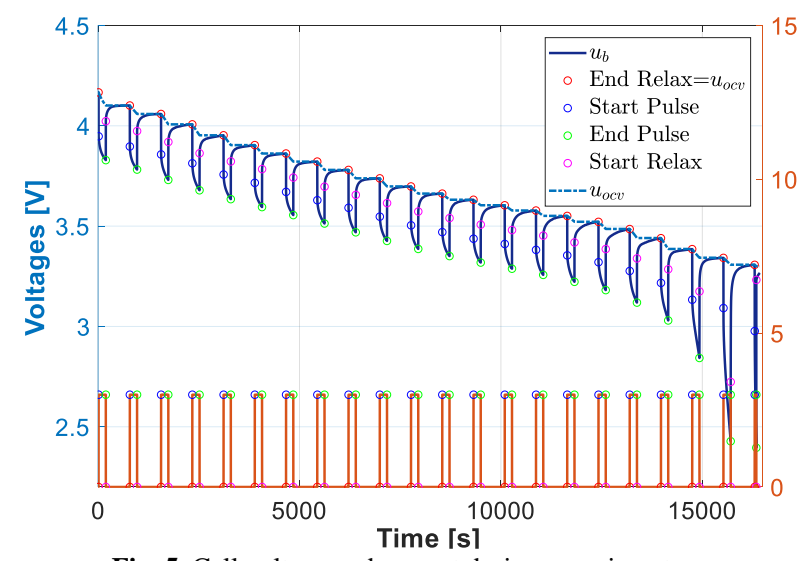

Fig. 5. Cell voltage and current during experiment.

The cell under test was first fully charged and then exposed to current pulses of $3 \mathrm{~A}(\sim 0.9 \mathrm{C})$ and duration of 3 minutes, which resulted in $\triangle \mathrm{SoC}$ of approximately $4.5 \%$ and $\mathrm{N}=21$ pairs of $\mathrm{CP}$ and RP. The rest periods are 10 minutes long, same as in [11], which led to total experiment time of $5 \mathrm{~h}$. The temperature dependence was not considered in this study, and the experiment was done at ambient temperature. Also, only discharging pattern was examined. The cell voltage and current waveforms during the experiment, along with relevant points necessary for data processing, are shown in Fig. 5. The $\mathrm{u}_{\mathrm{ocv}}$ is extracted from the end of RPs whereas $R_{o}$ is calculated using (1). The $u_{o c v}(\mathrm{SoC})$ and $\mathrm{R}_{0}(\mathrm{SoC})$ are plotted in Fig. 6 . 

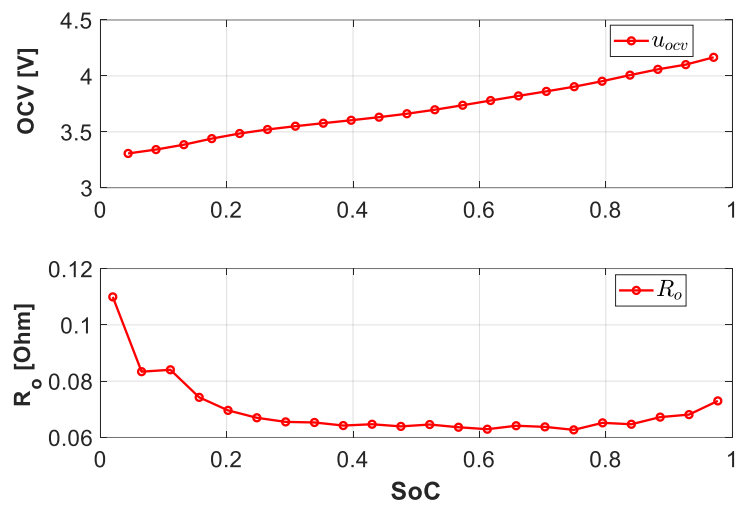

Fig. 6. The $\mathrm{u}_{\mathrm{ocv}}$ and $R_{o}$ with respect to $\mathrm{SoC}$.

Following the identification of OCV and internal resistance, the voltage over the RC chain, i.e. $\mathrm{u}_{\tau}$, was calculated using (2) and it is given in Fig. 7. Once $u_{\tau}$ is obtained during both pulse and relax periods, it is used as an input for parameter extraction procedure as explained in Section IV. Algorithm was implemented in MATLAB ${ }^{\circledR}$ Script Editor. Fitting procedures itself were carried out using fittype and fit functions. Lower and upper boundary conditions for all parameters are set to 0 and 1 , respectively. Furthermore, a trust-region algorithm is used.

Finally, the last parameters to be found were polarisation resistances and capacitances using (6) and (7), and they are shown in Fig. 8 and Fig. 9 for both pulse and rest periods in relation to SoC. As mentioned before, the SoC changes during

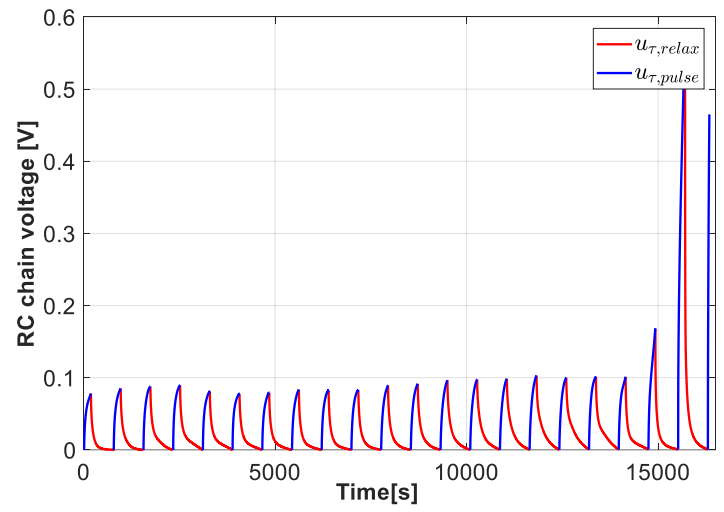

Fig. 7. The $R C$ voltage waveform $u_{\tau}$ during both $\mathrm{CP}$ and $\mathrm{RP}$
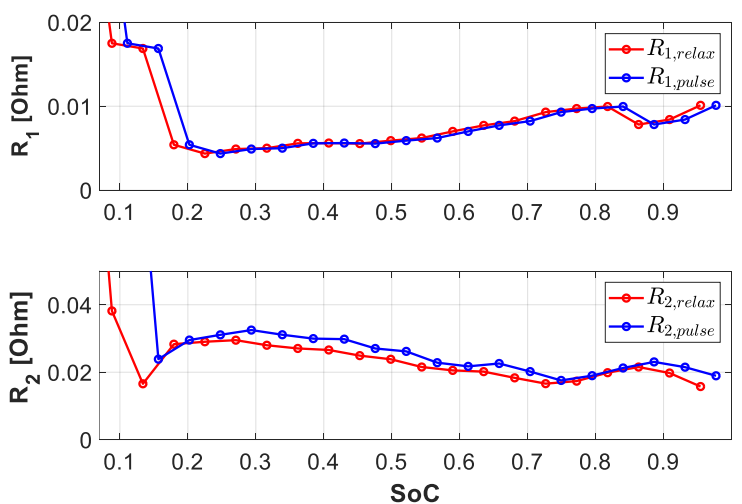

Fig. 8. $R_{1}$ and $R_{2}$ parameters of the model with respect to $S o C$.
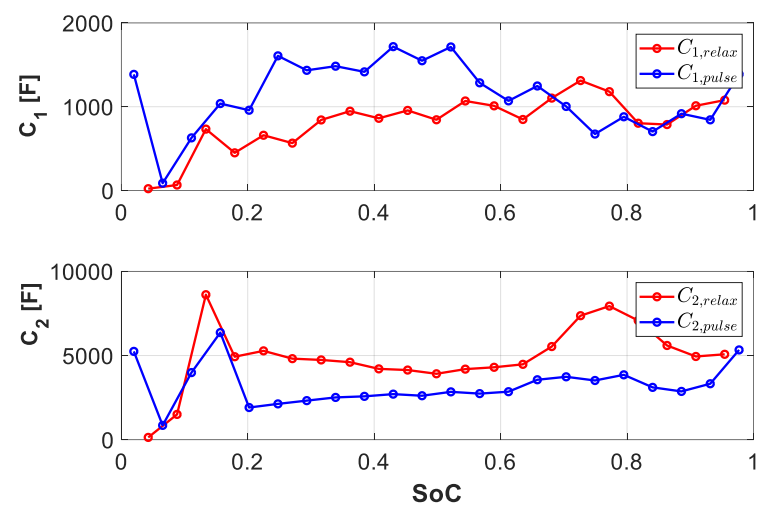

Fig. 9. $C_{1}$ and $C_{2}$ parameters of the model with respect to $S o C$.

$\mathrm{CP}$, so parameters estimated over current pulse are assigned to the average value $\left(\mathrm{SoC}_{\mathrm{a}}+\mathrm{SoC}_{\mathrm{b}}\right) / 2$, where $\mathrm{SoC}_{\mathrm{a}}$ and $\mathrm{SoC}_{\mathrm{b}}$ are values at the beginning and at the end of $\mathrm{CP}$.

\section{B. Simulation results}

Employing the estimated parameters, the model of the tested cell is created in the PLECS ${ }^{\circledR}$ environment using lookup tables, controlled sources and variable resistors and capacitors (Fig. 10). In the simulation model, a battery load profile identical to the experimental one is considered. The SoC is continuously calculated using coulomb counting method and model parameters are updated accordingly considering SoC and current rate. Voltages from the model and from the experiment are compared in Fig. 11 together with the error. Additionally,

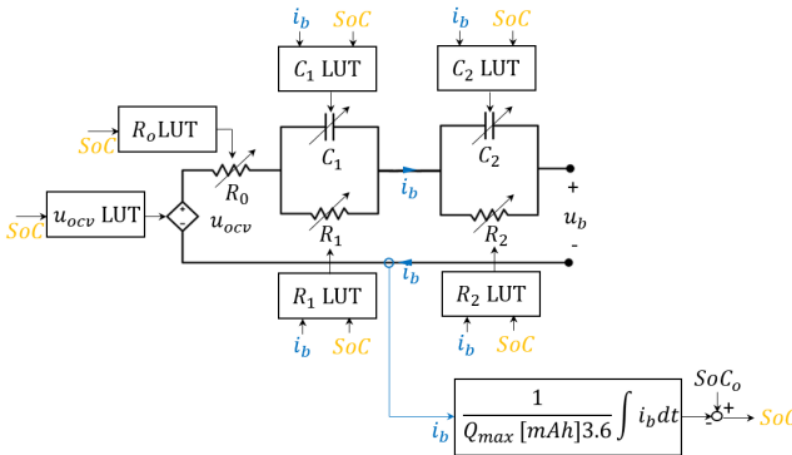

Fig. 10. Schematics of the complete ECM of Panasonic NCR18650B.
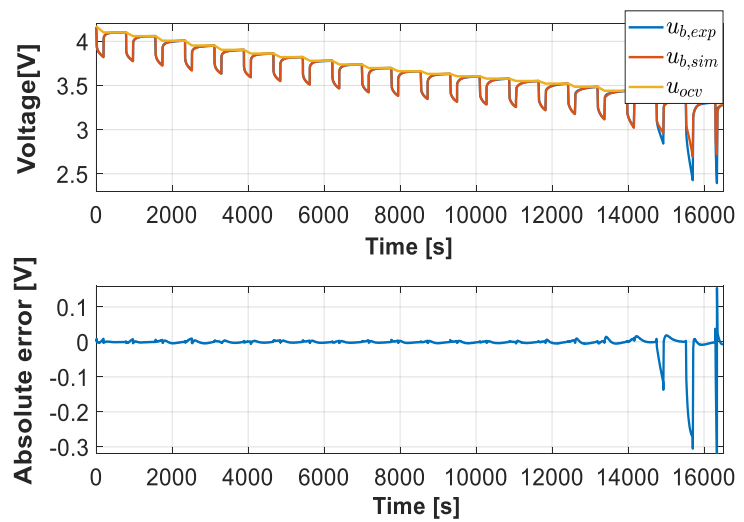

Fig. 11. Simulated and experimental cell voltage (up) and error (below). 
conventional model using analytical approach [12] is created and compared with the developed one. The voltages and errors are shown in Fig. 12. and Fig. 13.

It can be noticed that absolute error considerably increases below $15 \%$ SoC for both methods. Over the whole SoC range novel method performs better in terms of the maximum absolute error $\left(\mathrm{M}_{\mathrm{x}} \mathrm{AE}\right)$. However, with regards to the mean absolute error (MAE) and to the root-mean-square error (RMSE) conventional method outperforms the novel one $(5.6 \mathrm{mV}$ compared to $6.1 \mathrm{mV}$ for MAE and $25.9 \mathrm{mV}$ compared to $27.7 \mathrm{mV}$ for RMSE). On the

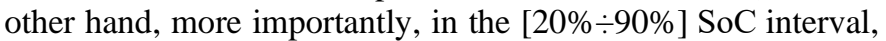
in which batteries are usually operated, novel approach showed better performance for all three error types as it can be seen in Table II and Fig. 12 and Fig. 13.

TABLE II. ERRors USING NOVEl AND CONVENTIONAL METHOD

\begin{tabular}{|c|c|c|}
\hline Feature & Novel & Conventional \\
\hline $\mathrm{M}_{\mathrm{x}} \mathrm{AE}_{(0 \%, 100 \%)}[\mathrm{V}]$ & $\mathbf{0 . 3 2 5}$ & 0.514 \\
\hline $\mathrm{M}_{\mathrm{x}} \mathrm{AE}_{(20 \%, 90 \%)}[\mathrm{mV}]$ & $\mathbf{1 4 . 6}$ & 41.4 \\
\hline $\mathrm{MAE}_{(0 \%, 100 \%)}$ & 6.1 & $\mathbf{5 . 6}$ \\
\hline $\mathrm{MAE}_{(20 \%, 90 \%)}$ & $\mathbf{2 . 1}$ & $\mathbf{2 . 1}$ \\
\hline $\operatorname{RMSE}_{(0 \%, 100 \%)}[\mathrm{mV}]$ & 27.7 & $\mathbf{2 5 . 9}$ \\
\hline $\operatorname{RMSE}_{(20 \%, 90 \%)}[\mathrm{mV}]$ & $\mathbf{2 . 7}$ & 4.3 \\
\hline
\end{tabular}
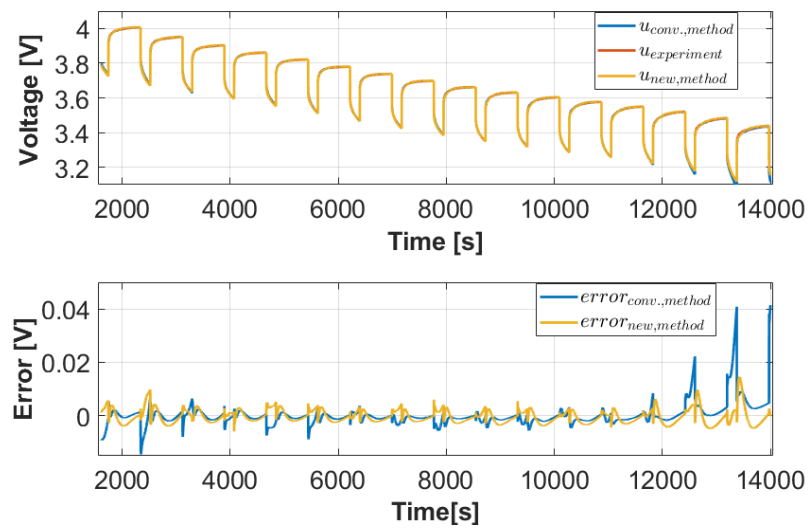

Fig. 12. Simulated and experimental cell voltage (up) and error (below) between $20 \%$ and $90 \%$ SoC
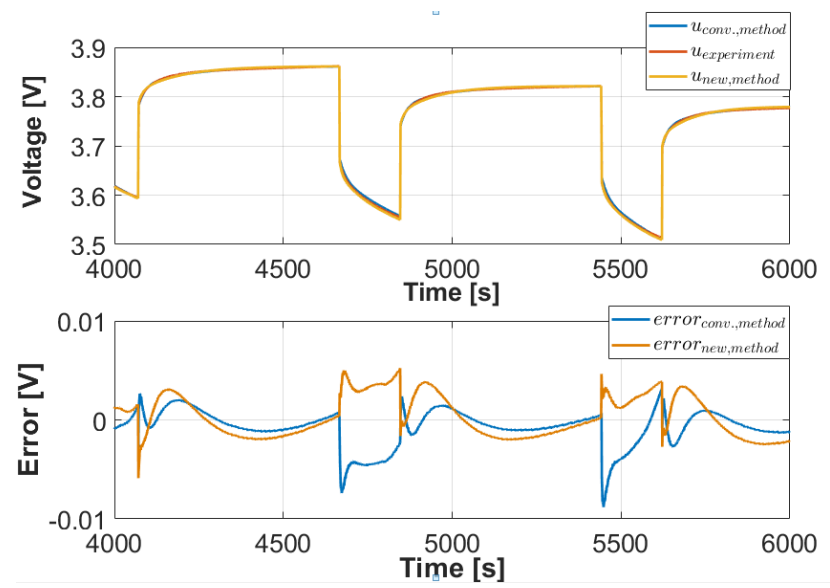

Fig. 13. Simulated and experimental cell voltage (up) and error (below) between 4000s and 6000s.

\section{CONCLUSIONS}

In this paper, a battery parameter estimation technique for the equivalent circuit modelling approach was presented. The method is based on fitting double exponential functions to the experimentally obtained (i.e., current pulse/rest period procedure) battery terminal voltage curve. In this methodology, the terminal voltage is approximated during both pulse and rest periods contrary to other estimation methods, i.e., parameters of the equivalent circuits are also obtained during the presence of current. In practice, 2D lookup tables were created which estimated parameters based on the battery current and state of charge. In addition, the initial voltages of $\mathrm{RC}$ branches were calculated analytically, and no assumptions had been made regarding the dynamics of mentioned RC circuits. Another benefit of this technique is that it doesn't require change in experimental part of the estimation process. In the end, the proposed procedure was verified by creating a model of Panasonic NCR18650B cell and results showed excellent matching between simulation and experiment results during both pulse and rest periods.

\section{REFERENCES}

[1] M. Lukic, P. Giangrande, C. Klumpner, and M. Galea, "Analysis of Energy Storage System Requirements for Aircraft Electric Taxiing Operations," IECON 2019 - 45th Annu. Conf. IEEE Ind. Electron. Soc., vol. 1, pp. 2616-2621, 2019.

[2] M. Lukic, P. Giangrande, A. Hebala, S. Nuzzo, and M. Galea, "Review, Challenges, and Future Developments of Electric Taxiing Systems," IEEE Trans. Transp. Electrif., vol. 5, no. 4, pp. 1441-1457, 2019.

[3] C. Klumpner and M. Rashed, "Design and evaluation of an energy storage system for helicopters," J. Eng., vol. 2019, no. 17, pp. 3665-3670, 2019.

[4] J. Meng, G. Luo, M. Ricco, M. Swierczynski, D. I. Stroe, and R. Teodorescu, "Overview of Lithium-Ion battery modeling methods for state-of-charge estimation in electrical vehicles," Appl. Sci., vol. 8, no. 5, 2018.

[5] M. V. Morganti, S. Longo, M. Tirovic, C. Y. Blaise, and G. Forostovsky, "Multi-Scale, Electro-Thermal Model of NMC Battery Cell," IEEE Trans. Veh. Technol., vol. 68, no. 11, pp. 10594-10606, 2019.

[6] R. Gu, P. Malysz, H. Yang, and A. Emadi, "On the suitability of electrochemical-based modeling for lithium-ion batteries," IEEE Trans. Transp. Electrif., vol. 2, no. 4, pp. 417-431, 2016.

[7] G. Fan, X. Li, and M. Canova, "A reduced-order electrochemical model of li-ion batteries for control and estimation applications," IEEE Trans. Veh. Technol., vol. 67, no. 1, pp. 76-91, 2018.

[8] R. Zhang et al., "Study on the characteristics of a high capacity nickel manganese cobalt oxide (NMC) lithium-ion battery-an experimental investigation," Energies, vol. 11, no. 9, 2018.

[9] I. Baccouche, S. Jemmali, B. Manai, N. Omar, and N. Essoukri Ben Amara, "Improved OCV model of a Li-ion NMC battery for online SOC estimation using the extended Kalman filter," Energies, vol. 10, no. 6, pp. 1-22, 2017.

[10] R. O. Nemes, S. Maria Ciornei, M. Ruba, and C. Martis, "Parameters identification using experimental measurements for equivalent circuit Lithium-Ion cell models,” 2019 11th Int. Symp. Adv. Top. Electr. Eng. ATEE 2019, pp. 1-6, 2019.

[11] M. Chen, S. Member, and G. A. Rinc, "Accurate Electrical Battery Model Capable of Predicting Runtime and I - V Performance," IEEE Trans. Energy Convers., vol. 21, no. 2, pp. 504-511, 2006.

[12] A. Hentunen, T. Lehmuspelto, and J. Suomela, "Time-domain parameter extraction method for thévenin-equivalent circuit battery models," IEEE Trans. Energy Convers., vol. 29, no. 3, pp. 558-566, 2014.

[13] L. Zhang, H. Peng, Z. Ning, Z. Mu, and C. Sun, "Comparative research on RC equivalent circuit models for lithium-ion batteries of electric vehicles," Appl. Sci., vol. 7, no. 10, 2017.

[14] T. Hu, B. Zanchi, and J. Zhao, "Simple analytical method for determining parameters of discharging batteries," IEEE Trans. Energy Convers., vol. 26, no. 3, pp. 787-798, 2011. 